\title{
A Systematic Review of Effect of Prenatal Zinc Supplementation on Birthweight: Meta-analysis of 17 Randomized Controlled Trials
}

\author{
Samson G. Gebreselassie' and Fikre E. Gashe ${ }^{2}$
}

\begin{abstract}
'Awassa College of Agriculture, Hawassa University, Ethiopia and ${ }^{2}$ School of Public Health, Addis Ababa University, Ethiopia
\end{abstract}
\begin{abstract}
The effect of prenatal zinc supplementation on birthweight is controversial as randomized controlled trials (RCTs) report conflicting conclusions. A systematic review which includes meta-analysis was done on 17 RCTs conducted worldwide since 1984 to assess the effect of prenatal zinc supplementation on birthweight. The studies were identified through web-based search. Heterogeneity among studies was assessed using Cochrane $\mathrm{Q}$ test statistic. Effect-size was measured based on standardized mean difference. Pooled effect-size was computed using a variant of random effect model. Thirteen of the 17 RCTs found no association, three reported positive association, and one reported negative association. Based on fixed and random effect models, the pooled effect-sizes were 0.0268 [95\% confidence interval (CI) $0.0764,-0.0229$ ) and 0.0712 $(95 \%$ CI $0.1619,-0.0194)$ respectively. The effect-size estimate remains insignificant after stratification was made based on the dose of supplementation (optimal vs high dose), type of study (community vs institution-based), and type of source country (developed vs developing). The meta-analysis did not witness any association between birthweight and prenatal zinc supplementation.
\end{abstract}

Key words: Birthweight; Medical research; Meta-analysis; Impact studies; Randomized control trails; Systematic review; Zinc supplementation

\section{INTRODUCTION}

Zinc is one of the essential trace elements and a member of the major micronutrients which have attained prominence in human health and nutrition (1). It is required for many biological functions, including DNA synthesis, cell division, gene expression, and stabilization of molecular structures. It is also vital for the activity of more than 300 enzymes participating in the metabolism of macronutrients, micronutrients, and nucleic acids $(2,3)$. Since its importance for human physiology was identified in 1963, many studies witnessed its crucial importance for immune function, linear growth and gain in weight, and neuropsychological and cognitive functions of human beings. Its involvement in such diverse and fundamental activities probably accounts for its essentiality for all forms of life (3).

Correspondence and reprint requests should be addressed to:

Mr. Samson Gebremedhin

PO Box 12485

Addis Ababa

Ethiopia

Email: samsongmgs@yahoo.com

Fax: +25115517701
Poor maternal zinc status is associated with adverse pregnancy outcomes as zinc is assumed to be essential for normal foetal growth and development (4). Animal experiments indicate that severe prenatal zinc deficiency is associated with spontaneous abortion and congenital malformations (5) whereas milder forms are attributed to low birthweight (LBW), intrauterine growth retardation (IUGR), and preterm delivery (6). Difficult and prolonged labour, haemorrhage, uterine dystocia, and placental abruption have also been documented in female rats fed zinc-deficient diets throughout pregnancy (7). The poor pregnancy outcomes in women with acrodermatitis enteropathica are also consistent with effects observed in zinc-deficient pregnant animals (8). However, studies that attempted to evaluate the effect of prenatal zinc status on maternal health and pregnancy outcomes in apparently healthy individuals yielded conflicting conclusions (9).

As to the effect of prenatal zinc supplementation on anthropometric indicators is concerned, of more than 20 RCTs conducted so far, few reported positive association between zinc supplementation and anthropometric measurements. According to a study in India, birthweight of infants born to women in the placebo group averaged only $2.6 \mathrm{~kg}$ 
(10). Infants born to zinc-supplemented mothers were $0.3-0.8 \mathrm{~kg}$ heavier, depending on the length of time supplemental zinc was provided for. If zinc supplementation was initiated in the first trimester, the effect on birthweight would be greater than if it was initiated in the third trimester (10). A study in the USA among disadvantaged African-American women reported that supplemented zinc increased birthweight by $126 \mathrm{~g}$ and increased head-circumference of infant by $0.4 \mathrm{~cm}$ (11). Another study in the USA (12) and a study in Chile (13) reported that zinc supplementation enhanced birthweight significantly-approximately by 150 and $69 \mathrm{~g}$ respectively. A study in Iran found significantly higher head-circumference of newborns in the supplemented group than in the control group $35.0 \mathrm{~cm}$ vs $33.7 \mathrm{~cm}$ ) but no increments in birthweight (14). However, the remaining RCTs failed to witness any association between anthropometric indicators and prenatal zinc supplementation (15-25).

The objective of this systemic review and metaanalysis was to examine the effect of prenatal zinc supplementation on birthweight. A similar metaanalysis was published in 2009 by the Cochrane Collaboration Group (26). However, this analysis has included four more additional studies and provided the results based on both fixed and random effect models.

\section{MATERIALS AND METHODS}

\section{Study design}

This is a systematic review which includes a metaanalysis.

\section{Inclusion and exclusion criteria}

To assure the quality of analysis, only RCTs were included in the analysis. Articles written in only English language were considered. The exclusion criteria were set based on multiple criteria, including low dose of supplementation (less than $15 \mathrm{mg}$ / day), unavailability of vital information in the articles (mean and standard deviation of birthweight in intervention and control arms, percentage of LBW babies in both arms) and low level of compliance $(<70 \%)$ for the supplement.

\section{Search strategy and evaluation of studies}

Studies were mainly identified through web-based descendent (identifying key literature and look online the other studies which cite them) and ancestor (look into the references of a key article) search techniques. The study did not involve any manual search of articles or contacts with authors. The elec- tronic search was performed within the Cochrane Library and MEDLINE databases. Further studies were identified using the Google Scholar search engine. Key combination search terms were "zinc supplementation and birthweight" and "zinc supplementation and birth outcomes". Literature written in only English language were considered, and no limit was made on date of publication of the articles.

Initially, 21 (20 published and $1 \mathrm{PhD}$ dissertation) articles and abstracts based on RCTs were located. The principal investigators reviewed all of them using the predefined inclusion criteria. They also checked quality of the studies in terms of reasonable level of compliance for the supplementation ( $>70 \%$ compliance), follow-up ( $<30 \%$ loss to follow- up), and assuring the comparability of the intervention and control groups based on key variables (maternal age, educational status, maternal anthropometric indicators, gestational age, parity, etc.). Disagreements were solved by repeated evaluations and discussions.

Three of the 21 RCTs, conducted in Germany (27), USA (28) and Denmark (29), were excluded as vital information, such as mean and standard deviation of birthweight in intervention and control arms and proportion of LBW babies in both arms, could not be extracted from the articles and abstracts. A study in South Africa was also excluded since it used very low dose (4.3-12.9 mg/day) of zinc supplementation (30). Hence, the analysis was done with the remaining 17 studies.

From each of the studies included, information on total number of zinc-supplemented and control children, number of LBW babies $(<2,500 \mathrm{~g})$, mean birthweight and standard deviation (SD) for both arms, nature of the population, and dose and duration of supplementation were extracted.

\section{Analysis of data}

The description of original studies was made using frequency and forest plot. Heterogeneity among studies was statistically assessed using Cochrane Q test statistic. The test statistic indicated random heterogeneity among studies $(\mathrm{p}=0.09)$. Hence, random effect model was used in the analysis. Among studies, variation was assessed using DerSimonian and Laird's (DL's) estimator. To control the effect of dose of supplementation (optimal or high dose), type of the study (community or institution-based), and type of source country (developed or developing), stratified analysis was made. We analyzed data using Metaeasy add-in for the MS Excel software (version 1.0). As relatively fewer articles were included 
in the analysis, Funnel plot was not used for assessing publication bias.

The strength of association between zinc supplementation and birthweight was assessed using effect-size which measures the strength or magnitude of difference between two sets of data (in this case treatment groups). It is the difference between the mean values of the two groups, divided by the standard deviation. The larger the effect-size, the greater is the difference or impact of an intervention. Cohen proposed operational definitions of $0.2,0.5$, and 0.8 as small, medium, and large effectsizes respectively (31).

\section{RESULTS}

\section{Description of original studies}

Four studies from the USA, three from the UK, six from Asian countries, three from Latin American countries, and only one from Africa were included in the analysis. In total, these studies involved 6,209 pregnant women in intervention and control arms. The sample-size of the studies ranged from 1,075 in Nepal (32) to 52 in the UK (18). With the exception of six community-based studies, all were health institution-based. All the studies randomized the study subjects into intervention and control groups around the mid-point of the second trimester (16-20 weeks). The dose of the supplement in 12 studies was 15-25 mg/day. However, in the remaining five studies, a higher dose (25-62 $\mathrm{mg} /$ day) of supplementation was used. All the studies were published in the last 25 years (1984-2009). The basic information of each specific study is presented in Table 1.

\section{Pooled effect-size}

The effect-size estimate of the specific studies showed that the majority $(n=13)$ of the studies found no association between zinc supplementation and birthweight. Three studies reported positive association while one study reported negative association. Based on fixed and random effect model assumptions, the mean (pooled) effect-sizes were 0.0268 (95\% CI 0.0764, -0.0229) and 0.0712 (95\% CI $0.1619,-0.0194)$ respectively. In both the cases, the meta-analysis showed no significant association between birthweight and zinc supplementation. The specific and pooled effect-sizes are presented in the figure.

To control the possible effect of confounders, stratification was made based on type of country (developed or developing), dose of supplementation (optimal or high dose), and type of study (health institution-based or community-based). The classification into developed or developing country was made according to the World Bank cut-off point of gross national income per capita of US\$ 3,945 (33). The mean effect-sizes, based on the fixed and random effect models for the respective categories, are summarized in Table 2.

In all the categories, the Q test statistic was 0.5-0.05 and, as such, the random effect model was taken as the appropriate estimator of pooled effect-size. The stratification indicated that prenatal zinc supplementation was not associated with birthweight, irrespective of dose, type of study, and country.

\section{DISCUSSION}

Another meta-analysis of 14 RCTs conducted by Cochrane group also failed to show any association between prenatal zinc supplementation and birthweight (26). According to this study, the pooled difference in the mean birthweight between the zinc supplemented and the control group was $-10.59 \mathrm{~g}$ (95\% CI -36.71, 15.54). Of 10 studies conducted in populations with low serum zinc or low dietary zinc intake, the pooled difference in the mean birthweight between the zinc-supplemented and the control group was $-11.42 \mathrm{~g}(95 \% \mathrm{CI}-38.82$, to 15.98) (26). Of three studies conducted in population with normal zinc status or adequate dietary zinc intake, the pooled difference in the mean birthweight between the zinc-supplemented and the control group was-2.32 g (95\% CI -88.94, to 84.30). In both the strata, zinc supplementation had no association with birthweight (26).

However, the finding of the two meta-analyses was not consistent to what is documented by many observational studies. In Japan, Higashi A et al. have demonstrated that maternal serum zinc level in the second trimester was not related to birthweight of infants (34); however, zinc status in the third trimester was an important determinant. A case-control study in Tanzania reported that mothers with low zinc levels were 2.6 times more at risk of having LBW babies compared to those with normal zinc levels, and newborns with low zinc levels were 2.8 times more at risk of being born with low weight (35). A study in the USA also found that, among both white and black mothers, serum zinc concentration was significantly related to birthweight after various independent determinants of birthweight were controlled (36). A similar association was also documented by studies in Turkey (37), India (38), and China (39).

The discrepancy between the conclusion of this analysis and the findings of many observational 


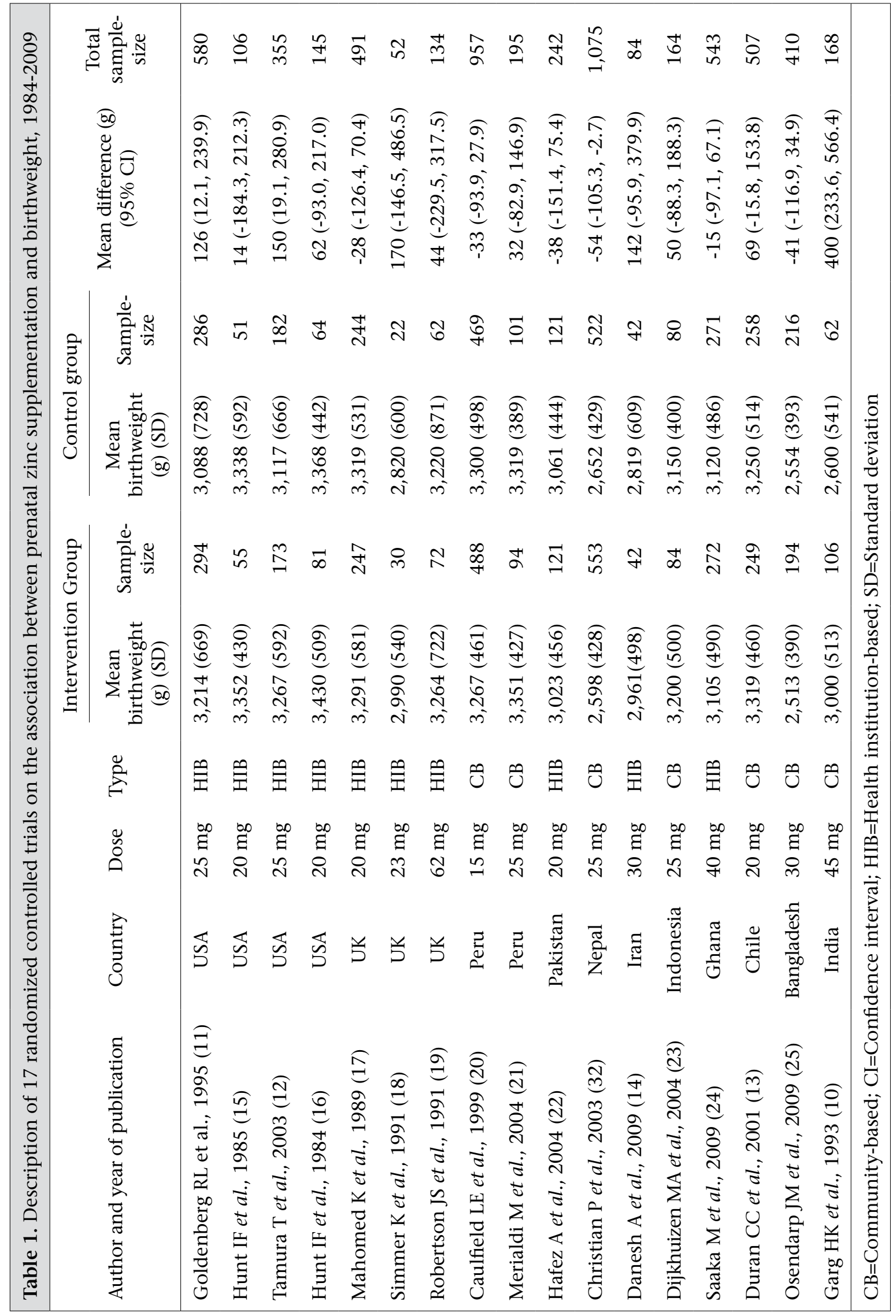




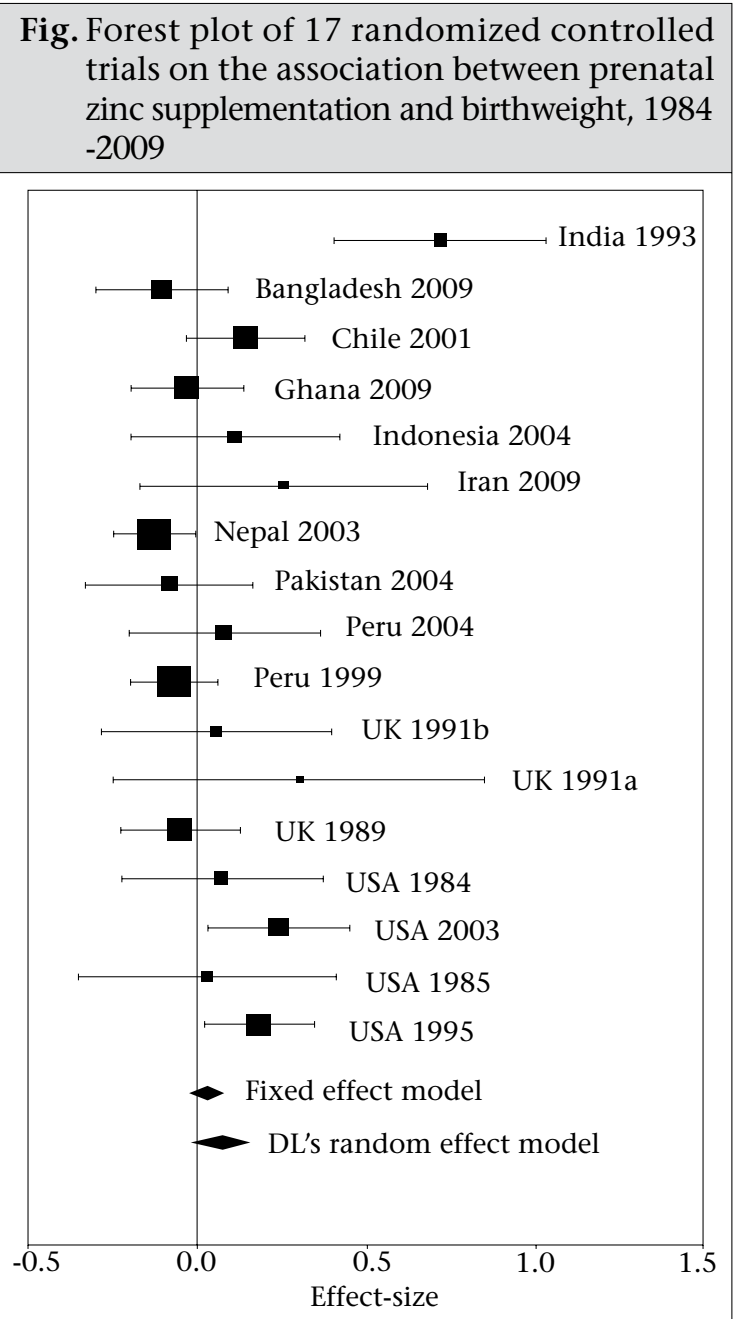

studies cannot be explained by non-compliance to zinc supplementation as all RCTs included in this other reason might be related to the bioavailability of zinc supplement. As absorption of dietary zinc can be inhibited by iron and phytate intake, the same might occur to zinc supplement. Hence, zinc level adequate to promote birthweight may not be achieved after the supplementation of zinc. This hypothesis is also supported by the findings of Hunt et al. in the USA (40). According to them, zinc supplementation among pregnant Hispanic women did not alter the mean zinc levels in serum or hair and did not increase the serum zinc level significantly compared to the pre-supplementation level (40).

As meta-analysis heavily depends upon published studies which are more likely to report significant results, non-significant studies which end up in the desk-drawer instead of the public domain would be systematically avoided. However, in this analysis, the problem of publication bias would be less significant as the focus of the analysis is a contemporary issue of scientific debate by which reporting any direction of association would be reasonably interesting to researchers and publishers.

\section{Conclusions}

The study did not witness any association between birthweight and zinc supplementation. However, the finding is not conclusive as possible confounding factors were not controlled. This does not mean that zinc status is not a possible predictor of birthweight as zinc supplementation status may not perfectly correlate with serum zinc level. The bioavailability of supplemental zinc should also be investigated.

Table 2. Mean effect-size in different categories of studies: 17 randomized controlled trials on the association between prenatal zinc supplementation and birthweight, 1984-2009

\begin{tabular}{|lccc|}
\hline Stratifying variable & $\begin{array}{c}\text { Total sample-size } \\
\text { of studies }\end{array}$ & $\begin{array}{c}\text { Effect-size with } \\
\text { 95\% CI } \\
\text { (fixed effect model) }\end{array}$ & $\begin{array}{c}\text { Effect-size with } \\
\text { 95\% CI } \\
\text { (random effect model) }\end{array}$ \\
\hline $\begin{array}{l}\text { Type of country } \\
\text { Developed }\end{array}$ & 1,863 & $0.107(0.197,-0.017)$ & $0.107(0.199,-0.016)$ \\
$\begin{array}{l}\text { Developing } \\
\text { Type of study }\end{array}$ & 4,345 & $-0.008(0.051,-0.068)$ & $0.057(0.183,-0.070)$ \\
$\quad$ Community-based & 3,476 & $0.101(0.174,0.026)$ & $0.129(0.267,-0.010)$ \\
$\quad$ Health institution-based & 2,732 & $-0.031(0.041,-0.103)$ & $0.075(0.268,-0.118)$ \\
$\begin{array}{l}\text { Dose of supplementation } \\
\text { 15-25 mg/day }\end{array}$ & 4,869 & $0.016(0.072,-0.040)$ & $0.040(0.123,-0.043)$ \\
26-62 mg/day & 1,339 & $0.067(0.175,-0.041)$ & $0.169(0.457,-0.119)$ \\
\hline CI=Confidence interval & & & \\
\hline
\end{tabular}

analysis reported a satisfactory level of compliance. One possible reason might be the risk of potential confounding bias in observational studies. The

\section{Conflict of interest}

The authors do not have any conflict of interest with regard to the findings of the study. 


\section{REFERENCES}

1. Hambidge M. Zinc and health: current status and future direction. J Nutr 2000;130:1344-9.

2. Prasad AS. Discovery of human zinc deficiency and studies in an experimental human model. Am J Clin Nutr 1991;53(2):403-12.

3. Food and Agriculture Organization. Zinc. In: Human vitamin and mineral requirements. Bangkok: Food and Agriculture Organization, 2002. (www.fao.org/ docrep/004/Y2809E/y2809e0m.htm\#bm22.1, accessed on 25 October 2009).

4. Shah D, Sachdev HP. Effect of gestational zinc deficiency on pregnancy outcomes: summary of observation studies and zinc supplementation trials. Br J Nutr 2001;85 (Suppl 2):S101-8.

5. Mambidge KM, Neldner KH, Walravens PA. Zinc, acrodermatitis enteropathica and congenital malformation (letter). Lancet 1975;1:577-8.

6. Jameson S. Zinc status in pregnancy: the effect of zinc therapy on perinatal mortality, prematurity and placental ablation. Ann N Y Acad Sci 1993;678:178-92.

7. Apgar J. Effect of zinc deficiency on parturition in the rat. Am J Physiol 1968;215:160-3.

8. King JC. Determinants of maternal zinc status during pregnancy. Am J Clin Nutr 2000;71(5 Suppl):1334-43.

9. Gibson RS. Zinc: the missing link in combating micronutrient malnutrition in developing countries. Proc Nutr Soc 2006;65:51-60.

10. Garg HK, Singhal KC, Arshad Z. A study of the effect of oral zinc supplementation during pregnancy on pregnancy outcome. Indian J Physiol Pharmacol 1993;37:276-84.

11. Goldenberg RL, Tamura T, Neggers Y, Cooper RL, Johnston KE, DuBard MB et al. The effect of zinc supplementation on pregnancy outcome. JAMA 1995;274:463-8.

12. Tamura T, Goldenberg RL. Zinc nutriture and pregnancy outcome. Nutr Res 1996;16:139-81.

13. Castillo-Durán C, Marin VB, Alcázar LS, Iturralde H, Ruz M. Controlled trial of zinc supplementation in Chilean pregnant adolescents. Nutr Res 2001;21:71524.

14. Danesh A, Janghorbani M, Mohammadi B. Effects of zinc supplementation during pregnancy on pregnancy outcome in women with history of preterm delivery: a double-blind randomized, placebo-controlled trial. J Matern Fetal Neonatal Med 2010;23:403-8.

15. Hunt IF, Murphy NJ, Cleaver AE, Faraji B, Swendseid ME, Browdy BL et al. Zinc supplementation during pregnancy in low-income teenagers of Mexican descent: effects on selected blood constituents and on progress and outcome of pregnancy. Am J Clin Nutr 1985;42:815-28.
16. Hunt IF, Murphy NJ, Cleaver AE, Faraji B, Swendseid ME, Coulson AH et al. Zinc supplementation during pregnancy: effects on selected blood constituents and on progress and outcome of pregnancy in lowincome women of Mexican descent. Am J Clin Nutr 1984;40:508-21.

17. Mahomed K, James DK, Golding J, McCabe R. Zinc supplementation during pregnancy: a double blind randomized controlled trial. BMJ 1989;299:826-30.

18. Simmer K, Lort-Phillips L, James C, Thompson RP. A double-blind trial of zinc supplementation in pregnancy. Eur J Clin Nutr 1991;45:139-44.

19. Robertson JS, Heywood B, Atkinson SM. Zinc supplementation during pregnancy. J Public Health Med 1991;13:227-9.

20. Caulfield LE, Zavaleta N, Figueroa A, Leon Z. Maternal zinc supplementation does not affect size at birth or pregnancy duration in Peru. J Nutr 1999;129:1563-8.

21. Merialdi M, Caulfield LE, Zavaleta N, Figueroa A, Costigan KA, Dominici F et al. Randomized controlled trial of prenatal zinc supplementation and fetal bone growth. Am J Clin Nutr 2004;79:826-30.

22. Hafeez A, Mehmood G, Mazha F. Oral zinc supplementation in pregnant women and its effect on birth weight: a randomized controlled trial. Arch Dis Child Fetal Neonatal Ed 2005;90:F170-1.

23. Dijkhuizen MA, Wieringa FT. Vitamin A, iron and zinc deficiency in Indonesia: micronutrient interactions and effects of supplementation. Wageningen: Wageningen University, 2001. 200 p. (PhD thesis).

24. Saaka M, Oosthuizen J, Beatty S. Effect of prenatal zinc supplementation on birthweight. J Health Popul Nutr 2009;27:619-31.

25. Osendarp SJ, van Raaij JM, Arifeen SE, Wahed M, Baqui AH, Fuchs GJ. A randomized, placebo-controlled trial of the effect of zinc supplementation during pregnancy on pregnancy outcome in Bangladeshi urban poor. Am J Clin Nutr 2000;71:114-9.

26. Mahomed K, Bhutta Z, Middleton P. Zinc supplementation for improving pregnancy and infant outcome: review. New York, NY: John Wiley and Sons, 2009:46-8.

27. Ross SM, Nel E, Naeye RL. Differing effects of low and high bulk maternal dietary supplements during pregnancy. Early Hum Dev 1985;10:295-302.

28. Cherry FF, Sandstead HH, Rojas P, Johnson LK, Batson HK, Wang XB. Adolescent pregnancy: associations among body weight, zinc nutriture and pregnancy outcome. Am J Clin Nutr 1989;50:945-54.

29. Jonsson B, Hauge B, Larsen MF, Hald F. Zinc supplementation during pregnancy: a double blind randomized controlled trial. Acta Obstetr Gynaecol Scandinavica 1996;75:725-9. 
30. Kynast G, Saling E. Effect of oral zinc application during pregnancy. Gynecol Obstet Invest 1986;21:117-23.

31. Grissom RJ and Kim JJ. Effect sizes for research: a broad practical approach. $2^{\text {nd }} \mathrm{ed}$. New Jersey, NJ: Lawrence Erlbaum Associates, 2005:98-117.

32. Christian P, Khatry SK, LeClerq SC, Shrestha SR, Kimbrough-Pradham E, West KP. Iron and zinc interactions among pregnant Nepali women. Nutr Res 2001;21:141-8.

33. World Bank. Data: how we classify countries. Washington, DC: World Bank, 2010. (http://data.worldbank.org/about/country-classifications, accessed on 12 July 2010).

34. Higashi A, Tajiri A, Matsukura M, Matsuda I. A prospective survey of serial maternal serum zinc levels and pregnancy outcome. J Pediatr Gastroenterol Nutr 1988;7:430-3.

35. Rwebembera AA, Munubhi EK, Manji KP, Mpembeni $\mathrm{R}$, Philip J. Relationship between infant birth weight $\leq 2000 \mathrm{~g}$ and maternal zinc levels at Muhimbili National Hospital, Dar Es Salaam, Tanzania. J Trop Pediatr
2006;52:118-25.

36. Yosadhara P, Ramaraju LA, Rashan L. Trace minerals in pregnancy: copper and zinc. Nutr Res 1991;11:1521.

37. Cavdar AO, Söylemez F, B. Cengiz B, Aydemir F. Zinc status during pregnancy: a longitudinal study. I Trace Elements in Experiment Med 2003;16:175-9.

38. Neggers YH, Cutter GR, Acton RT, Alvarez JO, Bonner JL, Goldenberg RL et al. A positive association between maternal serum zinc concentration and birth weight. Am J Clin Nutr 1990;51:678-84.

39. Ghosh A, Fong LY, Wan CW, Liang ST, Woo JS, Wong $\mathrm{V}$. Zinc deficiency is not a cause for abortion, congenital abnormality and small-for-gestational age infant in Chinese women. Br J Obstet Gynaecol 1985;92:88691.

40. Hunt IF, Murphy NJ, Cleaver AE, Faraji B, Swendseid $\mathrm{ME}$, Coulson $\mathrm{AH}$ et al. Zinc supplementation during pregnancy: zinc concentration of serum and hair from low-income women of Mexican descent. Am J Clin Nutr 1989;37:572-82. 